\title{
Application of Fuzzy Logic and Smartphone Accelerometer for DrivingCycle Determination
}

\author{
Adityo Suksmono, Abdul Halim and Mulyadi Sinung Harjono
}

\begin{abstract}
Smart driving and eco driving now become an important issue which they integrate environment, comfort, and safety riding. To achieve this condition, it is needed measurements or evaluations on our riding behaviour. One of parameters that describes our riding behaviour is driving cycle. The variable that is measured in driving cycle is the vehicle velocity in each second. In this research the velocity of vehicle was measured by accelerometer on a smartphone. The choice of using smartphone in this research was because it is used for communication tool by many people and equipped by many sensors such as accelerometer, magnetometer, and many other features. The biggest obstacle of using accelerometer as velocity measuring instrument was the measurement result is affected by drift, vibration, and earth gravitation. In this research, Fuzzy Logic was used to give correction on accelerometer reading in longitudinal direction which is affected by vibration and drift by looking at vibration in the lateral and vertical direction. Degree of membership (DOM) in each set which describes vehicle's movements and vibrations is determined based on sampling data and analyzed with Gauss Distribution that probability of acceleration which describes a state can be modelled. The accuracy of filtering is depend on filter design that we have made that covers range DOM on each defined state or sets, Membership Function, etc.
\end{abstract}

Index Terms - accelerometer; driving cycle, smartphone, Fuzzy Logic, Degree Of Membership (DOM), Membership Function.

\section{INTRODUCTION}

$\mathrm{D}$ RIVING cycle is a parameter that shows vehicle's velocity in particular duration. Based on driving cycle we would know the driver's behaviour. Driver's behaviour shows the way the driver controls the vehicle. Driver's behaviour determines the efficiency, the safety, and the environmental healthy. Moreover European Commission has determined to reduce carbon emission [1]. And also that Europe has determined standard driving to reduce carbon emission. Reducing emission has been implemented in many regions. To anticipate this condition otomotive producents must design the applications and the systems that can guide

Adityo Suksmono, is with Indonesian University. He is now with the Department of Electrical Engineering, Indonesian University, Depok, West Java, Indonesia (e-mail: adityosuksmono@yahoo.com).

Abdul Halim, is with Indonesian University. He is now with the Department of Electrical Engineering, Indonesian University, Depok, West Java, Indonesia.

Mulyadi Sinung Harjono, Transportation Infrastructure Laboratory Center of Technology for Systems and Infrastructure of Transportation, Agency for The Assessment and Application of Technology, Serpong, Banten, Indonesia. the drivers to have an efficient behaviour. That is when the drivers get the condition such as low fuel consumption, low emission, safety and low break component. In other hand smartphone has become a tool that can be applicated in many ways of our daily life. In the smartphone there are many inertial censors that has been installed such as accelerometer, gyroscope, and magnetometer. Based on this condition in this research we purposed to design a velocity measurement method using accelerometer in the smartphone.

Many problems and obstacles use inertial sensor like drift phenomena [2], interference vibration caused by engine and road surface [3], [4], [5], acceleration sensing interference with gravitation cause inclination [6], and accuration measurement that depends on temperature [7]. The acceleration that is because of drift phenomena causes oscillation acceleration although the accelerometer sensing is in static condition or constant velocity. This condition causes deviation that is when vehicle is in rest condition or moving in constant velocity, its sensing accelerometer shows change in longitudinal acceleration. Beside that longitudinal acceleration contains acceleration due to road surface vibration and engine vibration.

The objective of this research is to obtain an accurate acceleration measurement using accelerometer where fuzzy logic was used as the filter to correct longitudinal accleration based on lateral and vertical acceleration measurement to detect vibration and drift. The reason that Fuzzy Logic method is used in this research is because the accelerometer as a sensor has stochastic disturbance. However it has many obstacles but using accelerometer to determine driving cycle has many benefits which are cheaper, more practical, independent from electromagnetic interference and GPS signal, etc.

On the experiment, the velocity that is resulted from accelerometer sensing and GPS sensing would be compared in order to get accurate driving cycle. The accelerometer noises that was caused by temperature was ignored but still sampling data was undertaken in environment with low temperature to minimalize error. The experiment was taken on level and straight streets to avoid accelerometer reading correction because of gravitation and sentripetal acceleration force.

\section{HARDWARE, SOFTWARE AND NOISES}

Hardwares that are used in this research were accelerometer BMA 250 and GPS from smartphone Sony Xperia and Esia 
max-D respectively. Softwares that are used in this research were Sensor Kinetics Pro and GPS Logger to accussition data from smartphone in order to analyze it.

Accelerometer is an inertial sensor that senses linier acceleration that refers to inertial frame. This censor has many applications in Inertial Navigation for robotic for indoor use because of many obstacles to access GPS signal. In this research the accelerometer was used to determine the velocity of a motorcycle in body frame. It is not like navigation purpose which it uses accelerometer in which acceleration is referenced to particular frame (ECI, ECEF, etc). Therefore this research is not complicated as inertial navigation purpose, that needs coordinate transformation from inertial navigation frame to local frame and vise versa in order to know position. But that does not mean this research is very simple because to get an accurate velocity it must overcome noises that could cause drift, gravitation, and vibration. Then the velocity is determined by integralized the acceleration using this formula.

$$
\mathbf{v}(k+1)=\mathbf{v}(k)+\mathbf{a}(k) \cdot[t(k+1)-t(k)]
$$

If the acceleration and the time duration are known, using formula (1), the velocity will be known. Inaccurate acceleration measurement that is influenced by noises causes an increased error because the current velocity is determined from the previous velocity, and the next velocity is determined from current velocity so the error is accumulative.

Basically an accelerometer consists of proof mass, spring and damper. When an accelerometer senses acceleration, the proof mass deflects the spring because it receives a force, and based on this deflection, the force is known because the damper constant is known. Then the force is divided by mass of proof mass in order to get the acceleration. In MEMS, the accelerometer uses capasitor to replace spring but the principle is the same.

As discussed before, drift is a phenomenon where the output changes over time. However when a motorcycle is in rest it still shows that accelerometer is fluctuative as if the motorcycle is moving. Another noise is gravitation. A slope road makes gravitation component is in longitudinal axis that it causes bias in longitudinal acceleration. This is appropriate with formula (2) below. To obtain an acceleration from an accelerometer measurement it needs gravitation as an input. In other words to obtain an acceleration it needs an acceleration that is sensed by an accelerometer and local gravitation [8].

$$
\mathbf{a}_{\mathbf{i}}=\mathbf{f}_{\mathbf{i}}+\mathbf{g}_{\mathbf{i}}
$$

$a_{i}$ is acceleration referenced to Earth-centered inertial frame, $f_{i}$ is acceleration that is resulted from accelerometer sensing referenced to Earth-centered inertial frame, $\mathrm{g}_{\mathrm{i}}$ is gravitational acceleration referenced to Earth-centered inertial frame.

In a flat road which gravitational acceleration is perpendicular to local horizon there is no gravitational acceleration component which is related to longitudinal axis, so gravitational acceleration bias can be eliminated. But in a slope road we must compute gravitational acceleration component in longitudinal axis.
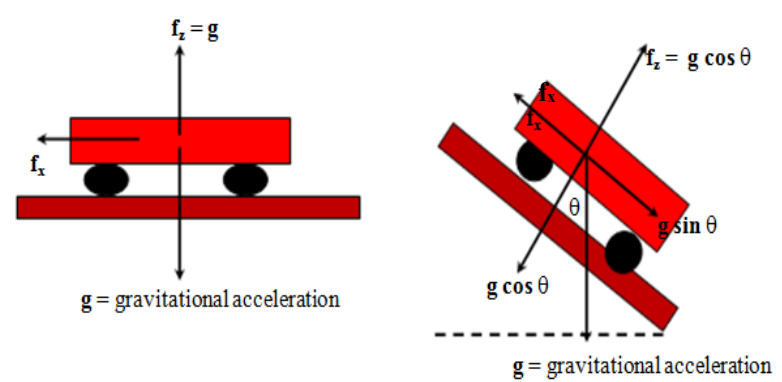

Fig. 1. There is gravitational acceleration component in longitudinal axis when vehicle is in slope road

The last noise, after gravitation and drift, that is concerned with this research is vibration. The vibration in the vehicle was influenced by engine and road surface vibration, so in this research, before the vehicle was run to measure acceleration in longitudinal, lateral, and vertical axis, sampling data of measurement influenced by engine vibration had been taken. Because many noises in measurement use accelerometer, Gaussian Distribution was used to identification particular noise from drift and vibration based on distribution acceleration.

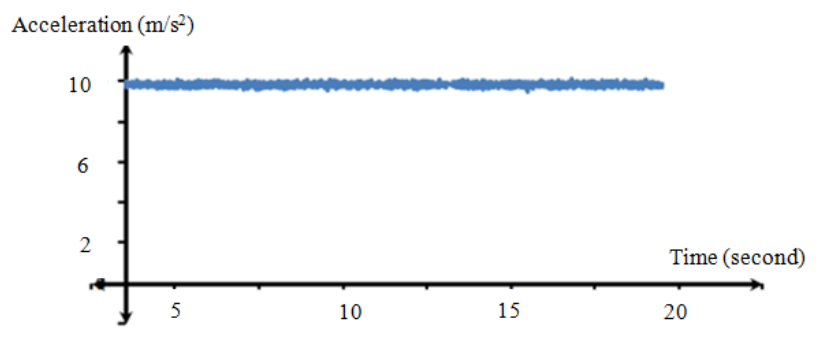

Fig. 2. Vertical axis acceleration that is resulted from accelerometer sensing in this experimentwas equal with gravitational acceleration when the vehicle was in rest in flat road

\section{EXPERIMENT}

In the experiment there were three states that was sampled by measurement acceleration in three axis accelerometer. The states were engine off, engine on, and running. Experiment was held out door with mounting accelerometer on flat base of motorcycle seat which was located at flat road. To reduce noises because of temperature, this experiment was held in the morning about $02.00 \mathrm{AM}$.

Sampling data of accelerometer measurement in engine off state was undertaken when motorcycle's engine is shut down. Sampling data of accelerometer measurement in engine on state was undertaken when motorcycle's engine is on but the motorcycle is in idle or no moving. Meanwhile sampling data of accelerometer measurement in running state is when the motorcycle is moving in a flat road. The road is $90 \mathrm{~m}$ paving block. Running state was designed in two scenarios which the first scenario was the motorcycle is moving with constant velocity $10 \mathrm{~km} /$ hour, and the second scenario was the motorcycle is moving with fluctuation velocity. The description of these scenarios can be seen in the Table I. 
TABLE I

DESCRIBE SCENARIO DRIVING CYCLE IN RUNNING STATE

\begin{tabular}{|c|c|c|}
\hline Parameter & Running I & Running II \\
\hline Velocity & Constan $10 \mathrm{~km} / \mathrm{jam}$. & Variated \\
\hline $\begin{array}{c}\text { Profil } \\
\text { velocity }\end{array}$ & &
\end{tabular}

TABLE II

NoISE In EVERy STAtes MEASUREMENTS IN THREE AXIS

\begin{tabular}{|c|c|c|c|}
\hline No & State & Accelerometer Axis & Quantity \\
\hline \multirow{3}{*}{1} & \multirow{3}{*}{ Engine off } & Longitudinal & Drift \\
\hline & & Lateral & Drift \\
\hline & & Vertikal & $\begin{array}{l}\text { Normal force due to gravitational } \\
\text { acceleration and drift }\end{array}$ \\
\hline \multirow{3}{*}{2} & \multirow{3}{*}{ Engine on } & Longitudinal & Drift and engine vibration \\
\hline & & Lateral & Drift and engine vibration \\
\hline & & Vertikal & $\begin{array}{l}\text { Nomal force due to gravitational } \\
\text { acceleration, Drift and engine vibration }\end{array}$ \\
\hline \multirow{3}{*}{3.} & \multirow{3}{*}{ Running } & Longitudinal & $\begin{array}{l}\text { Drift, accumulation engine vibration and } \\
\text { sufface road vibration, linier acceleration }\end{array}$ \\
\hline & & Lateral & $\begin{array}{l}\text { Drift, accumulation engine vibration and } \\
\text { surface road vibration. }\end{array}$ \\
\hline & & Vertikal & $\begin{array}{l}\text { Normal force due to gravitational } \\
\text { acceleration, drift, accumulation engine } \\
\text { vibration and surface road vibration. }\end{array}$ \\
\hline
\end{tabular}

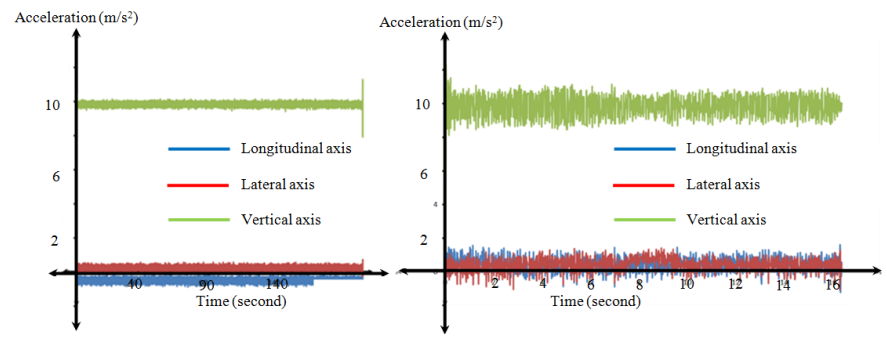

Fig.3 Acceleration in three axis sensed by accelerometer when engine is off and on state

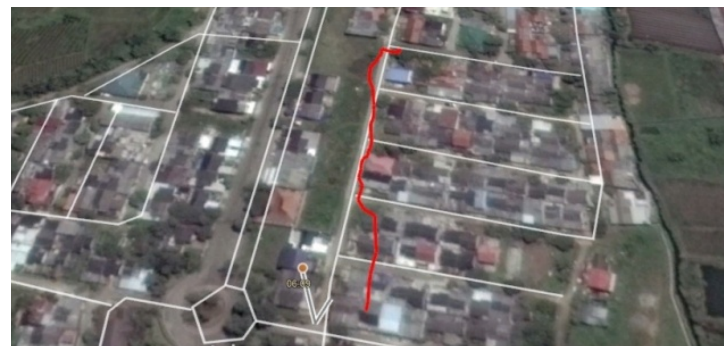

Fig. 4. GPS trackingwhen motorcycle is in running state

Sampling data analysis results spread acceleration data that has parameter like mean and variance which is known using statistical analysis. In this research we used Gaussian Distribution to predict which noise that would happen when the motorcycle is running in particular acceleration based on the spread data.

\section{GAUSSIAN DISTRIBUTION}

Data resulted in measurement experiment is analized using Gauss distribution to identify every noise. Gaussian distribution is used to determine probability in particular event which it is commonly used in statistical analysis. The form of this distribution is bell which the value in the center is mean $(\mu)$ and the spread of data is represented by standard deviation $(\sigma)$ in wich the mean and the standard deviation are identical with every noise described in previous discuss. If there are any data $\mathrm{x} 1, \mathrm{x} 2, \mathrm{x} 3, \ldots \mathrm{xn}$, where $\mathrm{n}$ is number data then mean and standard deviation can be computed. After mean and standard deviation are known, Gaussian distribution can be determined using this formula.

$$
f(x)=\frac{1}{\sigma \sqrt{2 \pi}} e^{-\frac{1}{2}\left(\frac{x-\mu}{\sigma}\right)^{2}}
$$

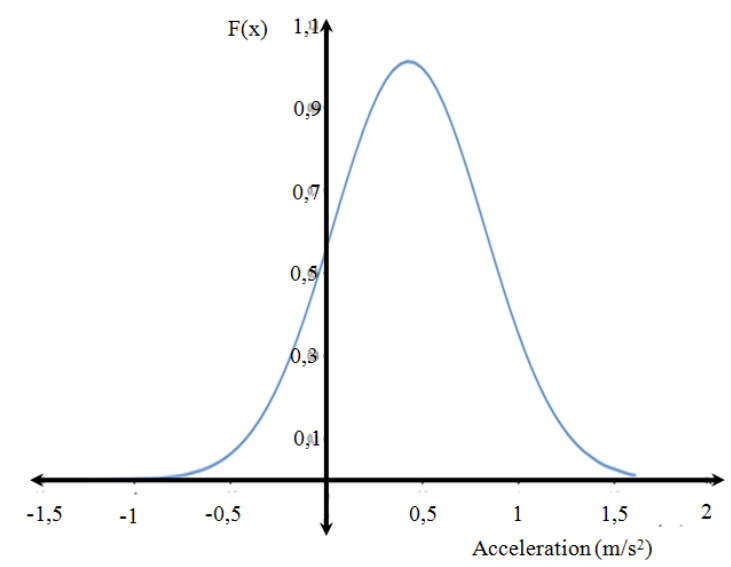

Fig. 5. Longitudinal acceleration Gaussian distribution resulted accelerometer sensing in this experiment

TABLE III

SAMPLING DATA ANALYSIS USING GAUSSIAN DISTRIBUTION

\begin{tabular}{|c|c|c|c|c|}
\hline State & Quantity & $\begin{array}{c}\text { Longitudinal } \\
\text { acceleration } \\
\left(\mathrm{m} / \mathrm{s}^{2}\right)\end{array}$ & $\begin{array}{c}\text { Lateral } \\
\text { acceleration } \\
\left(\mathrm{m} / \mathrm{s}^{2}\right)\end{array}$ & $\begin{array}{c}\text { Vertical } \\
\text { acceleration } \\
\left(\mathrm{m} / \mathrm{s}^{2}\right)\end{array}$ \\
\hline Engine Off & Mean & $-0,49 \mathrm{~m} / \mathrm{s} 2$ & $0,23 \mathrm{~m} / \mathrm{s} 2$ & $9,84 \mathrm{~m} / \mathrm{s} 2$ \\
\cline { 2 - 5 } & $\begin{array}{c}\text { Standard } \\
\text { deviation }\end{array}$ & $0,10 \mathrm{~m} / \mathrm{s} 2$ & $0,099 \mathrm{~m} / \mathrm{s} 2$ & $0,097 \mathrm{~m} / \mathrm{s} 2$ \\
\hline Engine On & Mean & $0,43 \mathrm{~m} / \mathrm{s}^{2}$ & $0,45 \mathrm{~m} / \mathrm{s}^{2}$ & $9,85 \mathrm{~m} / \mathrm{s}^{2}$ \\
\cline { 2 - 5 } & $\begin{array}{c}\text { Standard } \\
\text { deviation }\end{array}$ & $0,39 \mathrm{~m} / \mathrm{s}^{2}$ & $0,35 \mathrm{~m} / \mathrm{s}^{2}$ & $0,59 \mathrm{~m} / \mathrm{s}^{2}$ \\
\hline
\end{tabular}

When the accelerometer in each axis senses particular acceleration that its value is the same as mean drift noise Gauss distribution, we can conclude that motorcycle is in state engine off. So how if the accelerometer senses acceleration that is not equal to mean value in each axis? In this research we used Fuzzy Logic to determine motorcycle's state.

\section{FUZZY LOGIC}

A fuzzy logic can be defined as the nonlinear mapping of an input data set to a scalar output data [9]. Fuzzy logic consists of sequencial process those are fuzzification, fuzzy rules, inference engine, and defuzzification. In this research, fuzzification is undertaken with convert acceleration resulted accelerometer sensing into fuzzy set that defined every accelerometer axis using membership function.

TABLE IV

SETS THAT ARE DEFINED ON EACH AXIS

\begin{tabular}{|c|c|c|}
\hline No & Axis & Sets \\
\hline 1 & $\mathrm{X}$ (longitudinal) & $\begin{array}{l}\text { Uniform rectilinear and accelerated uniform } \\
\text { motion }\end{array}$ \\
\hline 2 & Y (lateral) & $\begin{array}{c}\text { Engine vibration and accumulation engine and } \\
\text { surface road vibration }\end{array}$ \\
\hline 3 & Z (vertical) & $\begin{array}{c}\text { Engine vibration and accumulation engine and } \\
\text { surface road vibration }\end{array}$ \\
\hline
\end{tabular}


After input data is obtained then using membership functions (MFs) to quantize degree of membership particular parameter input to particular set that is defined using, in this reesearch, linear function. It can be seen in Figure 6 below.

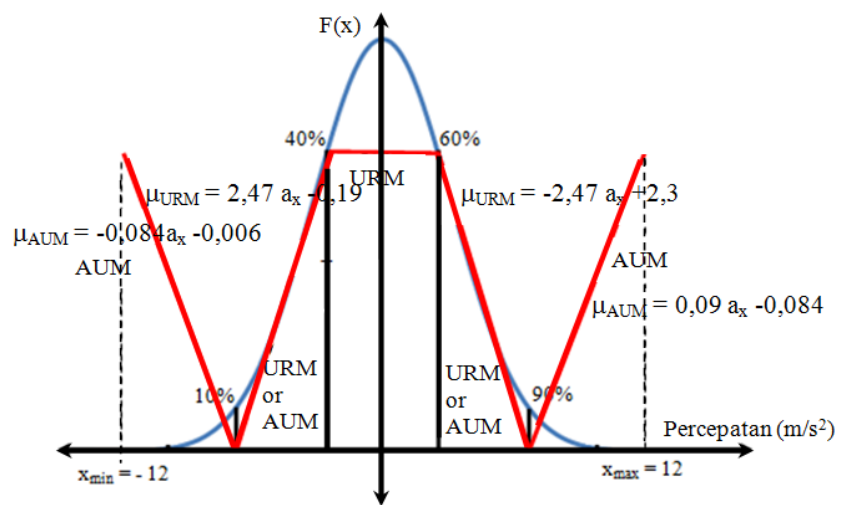

Fig. 6.Membership function represented by linier function

TABLE V

MEMBERSHIP FUNCTION IN LONGITUDINAL AXIS ACCELEROMETER ON ENGINE ON STATE

\begin{tabular}{|l|l|l|l|}
\hline No & Himpunan & Letak Pada Range percepatan & Membership Function \\
\hline 1. & URM & $\Phi^{-1}(40 \%) \leq \mathrm{a}_{\mathrm{x}} \leq \Phi(60 \%)$ & $\mu_{\mathrm{GLB}}=1$ \\
\hline 2. & URM & $\Phi^{-1}(60 \%) \leq \mathrm{a}_{\mathrm{x}} \leq \Phi(90 \%)$ & $\mu_{\mathrm{GLB}}=-2,47 \mathrm{a}_{\mathrm{x}}+2,30$ \\
\hline 3. & URM & $\Phi^{-1}(10 \%) \leq \mathrm{a}_{\mathrm{x}} \leq \Phi(40 \%)$ & $\mu_{\mathrm{GLB}}=2,47 \mathrm{a}_{\mathrm{x}}+0,19$ \\
\hline 4. & AUM & $\mathrm{x}_{\min } \leq \mathrm{a}_{\mathrm{x}} \leq \Phi(10 \%)$ & $\mu_{\mathrm{GLBB}}=-0,084 \mathrm{a}_{\mathrm{x}}-0,0065$ \\
\hline 5. & AUM & $\Phi(90 \%) \leq \mathrm{a}_{\mathrm{x}} \leq \mathrm{x}_{\max }$ & $\mu_{\mathrm{GLBB}}=0,09 \mathrm{a}_{\mathrm{x}}-0,084$ \\
\hline
\end{tabular}

After degree of membership every data is obtained then fuzzy rules is desained. Fuzzy rules is a rule base that is constructed to control the output variable. In this research fuzzy rules can be seen in Table.VI.

\begin{tabular}{|c|c|c|c|}
\hline \multicolumn{4}{|c|}{$\begin{array}{c}\text { TABLE VI } \\
\text { FUZZY RULES }\end{array}$} \\
\hline No & Himpunan & Letak Pada Range percepatan & Membership Function \\
\hline 1. & URM & $\Phi^{-1}(40 \%) \leq \mathbf{a}_{\mathbf{x}} \leq \boldsymbol{\Phi}(60 \%)$ & $\mu_{\mathrm{GLB} B}=1$ \\
\hline 2. & URM & $\Phi^{-1}(60 \%) \leq \mathrm{a}_{\mathbf{x}} \leq \boldsymbol{\Phi}(90 \%)$ & $\mu_{\text {GLB }}=-2,47 \mathrm{a}_{\mathrm{X}}+2,30$ \\
\hline 3. & URM & $\Phi^{-1}(10 \%) \leq \mathrm{a}_{\mathrm{x}} \leq \Phi(40 \%)$ & $\mu_{\text {GLB }}=2,47 \mathbf{a}_{\mathrm{x}}+0,19$ \\
\hline 4. & AUM & $\mathrm{x}_{\min } \leq \mathrm{a}_{x} \leq \Phi(10 \%)$ & $\mu_{\text {GLBB }}=-0,084 \mathrm{a}_{\mathrm{x}}-0,0065$ \\
\hline 5. & AUM & $\Phi(90 \%) \leq \mathrm{a}_{\mathrm{x}} \leq \mathrm{x}_{\max }$ & $\mu_{\text {GLBB }}=0,09 \mathrm{a}_{\mathrm{x}}-0,084$ \\
\hline \begin{tabular}{|l} 
Longitudinal Axis \\
\end{tabular} & LateralAxis & Vertical Axis & Command \\
\hline $\begin{array}{l}\text { Uniform Rectilinear } \\
\text { Motion (URM) }\end{array}$ & Engine vibration & Engine vibration & $\begin{array}{l}\text { Longitudinal acceleration= } \\
0 \mathrm{~m} / \mathrm{s} 2 \text { (Uniform } \\
\text { Rectilinear Motion) }\end{array}$ \\
\hline $\begin{array}{l}\text { Uniform Rectilinear } \\
\text { Motion(URM) }\end{array}$ & $\begin{array}{l}\text { Accumulation } \\
\text { engine and } \\
\text { surfaceroad } \\
\text { vibration }\end{array}$ & Engine vibration & $\begin{array}{l}\text { Little correction on } \\
\text { longitudinal acceleration }\end{array}$ \\
\hline $\begin{array}{l}\text { Uniform Rectilinear } \\
\text { Motion (URM) }\end{array}$ & Engine vibration & $\begin{array}{l}\text { Accumulation engine and } \\
\text { surface road vibration }\end{array}$ & \begin{tabular}{|l|} 
Little correction on \\
longitudinal acceleration
\end{tabular} \\
\hline $\begin{array}{l}\text { Uniform Rectilinear } \\
\text { Motion (URM) }\end{array}$ & $\begin{array}{l}\text { Accumulation } \\
\text { engine and } \\
\text { surface road } \\
\text { vibration }\end{array}$ & $\begin{array}{l}\text { Accumulation engine and } \\
\text { surface road vibration }\end{array}$ & $\begin{array}{l}\text { Rather large correction on } \\
\text { longitudinal acceleration }\end{array}$ \\
\hline $\begin{array}{l}\text { accelerated uniform } \\
\text { motion(AUM) }\end{array}$ & Engine vibration & Engine vibration & $\begin{array}{l}\text { Little correction on } \\
\text { longitudinal acceleration }\end{array}$ \\
\hline $\begin{array}{l}\text { accelerated uniform } \\
\text { motion(AUM) }\end{array}$ & $\begin{array}{l}\text { Accumulation } \\
\text { engine and } \\
\text { surface road } \\
\text { vibration }\end{array}$ & Engine vibration & \begin{tabular}{|l|} 
Large correction on \\
longitudinal acceleration
\end{tabular} \\
\hline $\begin{array}{l}\text { accelerated uniform } \\
\text { motion(AUM) }\end{array}$ & Engine vibration & $\begin{array}{l}\text { Accumulation engine and } \\
\text { surface road vibration }\end{array}$ & $\begin{array}{l}\text { Large correction on } \\
\text { longitudinal acceleration }\end{array}$ \\
\hline $\begin{array}{l}\text { accelerated uniform } \\
\text { motion(AUM) }\end{array}$ & $\begin{array}{l}\text { Accumulation } \\
\text { engine and } \\
\text { surface road } \\
\text { vibration }\end{array}$ & $\begin{array}{l}\text { Accumulation engine and } \\
\text { surface road vibration }\end{array}$ & $\begin{array}{l}\text { Very large correction on } \\
\text { longitudinal acceleration }\end{array}$ \\
\hline
\end{tabular}

The simple way to understand the role of fuzzy rules in this research is if the acceleration is in lateral axis and vertical axis classified as engine vibration we can conclude that surface road vibration is minor so aceeleration in longitudinal axis is reliable so that it needs very little correction or even no correction. If the acceleration is in $\mathrm{y}$ and $\mathrm{z}$ axis classified in accumulative engine and surface road vibration, the acceleration in $\mathrm{x}$ axis must be corrected. The correction value is determined by Fuzzy Rules.

In this research, based on fuzzy rule, fuzzy inference system is designed. Parameter that is resulted from fuzification is fuzzy input that becomes input inference engine where the output is fuzzy output that it will undergo defuzifikation to yield correction value to correct longitudinal acceleration.
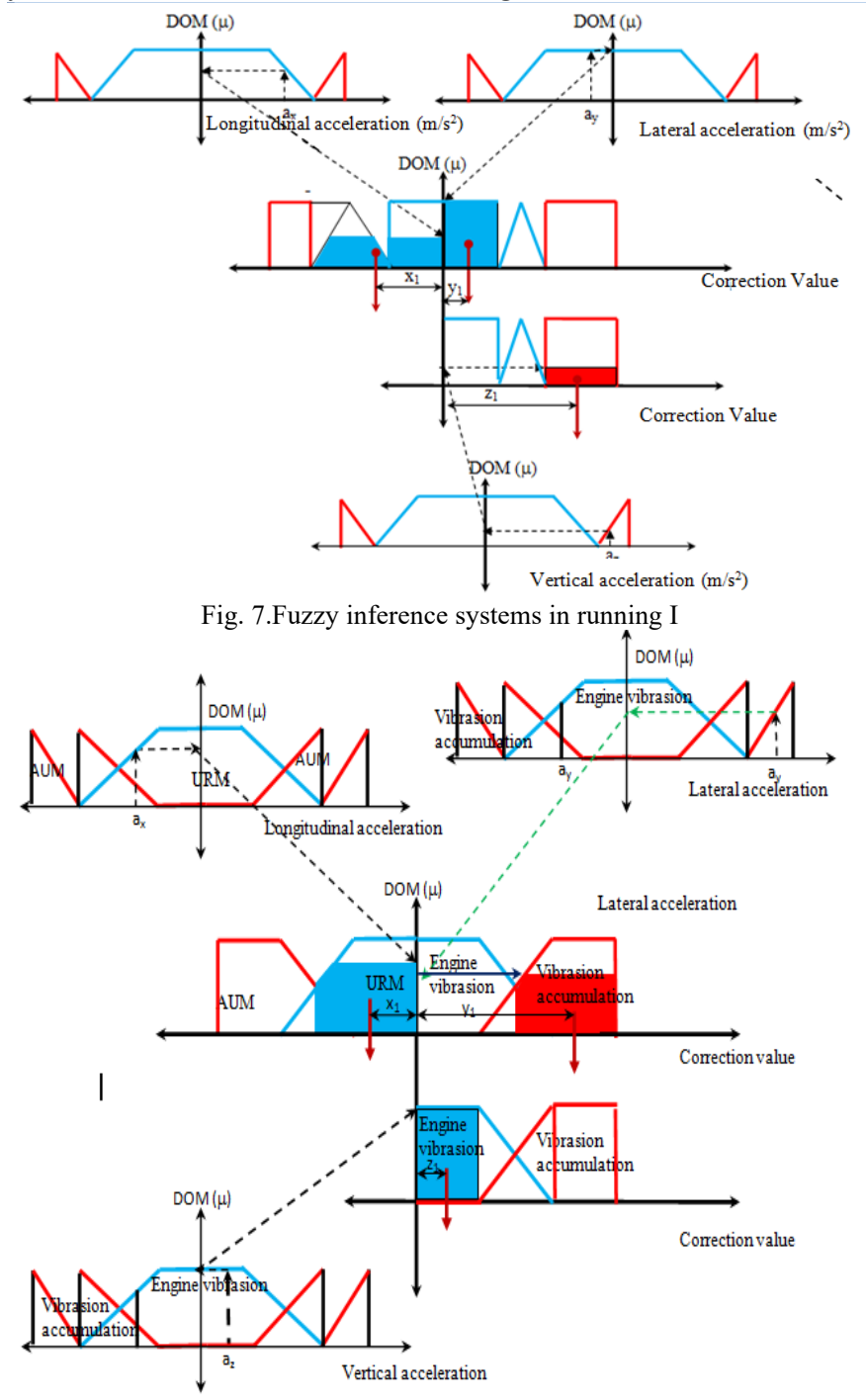

Fig. 8.Fuzzy inference systems in running II

The output value that is yielded is a correction value that will be multiplied with acceleration quantity resulted from accelererometer sensing in longitudinal axis. Correction value from accelerometer sensing is calculated with equation (4) below.

$$
\left(\frac{\mid \text { centroid } \mid}{x_{\max }}\right) \times a_{x}=a_{\mathrm{x}}^{\prime}
$$

$\mathrm{X}_{\max }$ is maximum scale that has been determined, $\mathrm{a}_{\mathrm{x}}$ is acceleration value resulted from accelerometer sensing in longitudinal axis, $a_{x}$ is accelertion value resulted from accelerometer sensing that has been corrected, centroid is absolut value from centroid. 


\section{ANALYSIS}

In the first running state, where the motorcycle runs at constant speed, the motorcycle experiences 3 moving phases, those are accelerated that is when it starts from rest, constant speed or uniform rectalinear motion when it runs in constant speed about $10 \mathrm{~km} /$ hour, and decelerated when it brakes or decreases speed in order to stop. In ideal condition (no noise), accelerometer will sense acceleration when motorcycle is accelerated and decelerated, and when motorcycle is at constant speed, the acceleraton is zero. Unfortunately, the ideal condition was not happened when experiment is undertaken.This is because of noises we have explained previously. Therefore acceleration data in longitudinal axis is corrected based on drift and vibration data which distribution of acceleration data in longitudinal, lateral, and vertical direction is known using Gaussian distribution. After longitudinal acceleration is obtained which has been corrected by fuzzy logic method, it is inputted to equation (1), so that velocity data in certain time is obtained. The comparison of driving cycle design, velocity resulted GPS sensing, and velocity resulted accelerometer sensing which is filtered by Fuzzy Logic can be seen in Figure 9 below.

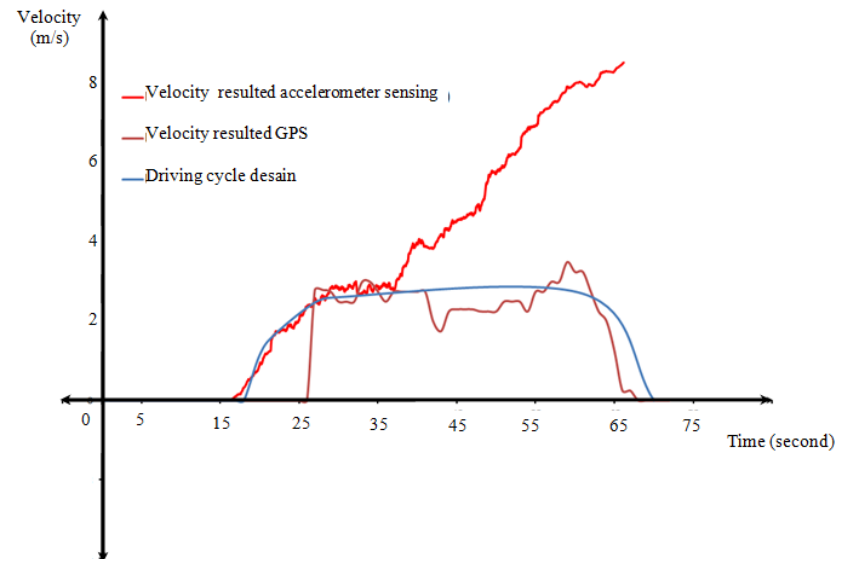

Fig. 9.Comparison of driving cycle analysis in running state I

Based on analitical result that can be seen in Figure 9 this method can predict the driving cycle in the 15th second to the 37 th second when the vehicle is accelerating from rest state to constant speed and when speeding (constant speed). But when the vehicle was moving, bias accumulated from dfrift, vibration, and inaccurate speed calculation previously caused error enlarging that after 37th second the deviation of the filtered speed resulted from fuzzy logic became larger against real velocity. Whereas the speed calculation using GPS is more stable, although the accuracy is not perfect.

The second running state, the speed of motorcycle was varied, then it was compared with speed from GPS and calculated from acceerometer sensing, and then it was filtered by fuzzy logic. Based on analitical result that is presented in Figure 10 it can be seen that generally the result is not similar but has similar trend. After 40th second the measurement result using accelerometer was not accurate because it had large deviation toward measurement using GPS. This is because bias accumulation resulted from drift, vibration and deviation accumulation toward speed calculation in previous interval. Nevertheless to determine driving cycle qualitatively and in macro and to detect whether the vehicle is accelerated, decelerated, or constant is quite promising because the trend is similar.

In the second running, the motorcycle speed was more varied compared the speed in the first running. It caused the fuzzy interference system in the second running had to accomodate many acceleration values in certain interval that it was intersection of two sets. The result was proven that fuzzy interference system is more adaptive in sensing changing speed.

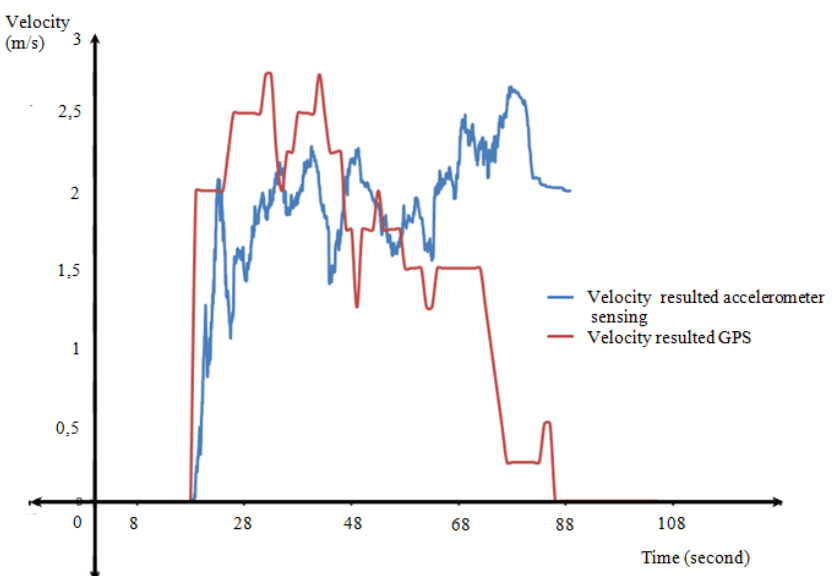

Fig. 10.Comparison of driving cycle analysis in running state II

In this research, road's condition was not smooth that some paving blocks that cover the road were damaged and there were some slopes in some area of the road. This road condition causes road surface vibration, as a result the measurement were not accurate. More over inaccurate previouse acceleration measurement causes velocity value calculated by equation (1) were not accurate. This inaccurate calculation is accumulative so that in certain time the speed deviation resulted from fuzzy logic analisys and the real speed became significant.

Fuzzy logic analysis that has been developed is not adaptive yet in encountering accumulative bias and changing speed in short interval. But if the speed of the vehicle is constant this method is precision enough to calculate the speed and detect whether there is acceleration. Even on the Figure 9 it can be seen fuzzy logic analysis in determining the speed when the vehicle was accelerated is more precise compared GPS analysis result in particular interval. $\mathrm{n}$ this research temperature that causes drift and gravitation that influences measurement in slope road were ignored. To get the presition result both quantity have to be modelled and measured.

\section{CONCLUSSION}

When the vehicle was running in constant speed, in the first running state, Fuzzy Logic could analyze velocity changes acurately in all phases that are in accelerated phase when the vehicle starts from rest to constant speed, in constant speed 
when the vehicle is running in constant speed, and in decelerated phase when the vehicle is decelerated and finally stops in particular time interval, rather than when the vehicle was running in variated speed in the second running state. This is because when the vehicle is running in constant speed configuration Fuzzy Logic is more adaptive to analyze simple acceleration changes in regular sequence that are mentioned before. When the vehicle is running in variated speed there are more complex acceleration changes that in short time interval the vehicle can change its acceleration. So it is necessary to choose proper fuzzy interference system which is corelated with fuzzy sets, intersection of two sets in fuzzification, and membership function that must be defined before. Even though it is not so accurate in quantitative analysis, Fuzzy Logic still can analyze velocity changes qualitatively in particular time interval when a vehicle is running in variated speed based on the trend of the gradient that is shown in grafik speed vs time. To improve the analysis it must be considered superposition vibrations that can be maximum interference and minimum interference in addition to variated fuzzy interference system to optimize the result.

\section{REFERENCES}

[1] T.J. Barlow, S. Latham, I.S.McCrae, P.G. Boulter, "A Referene Book of Driving Cycles for Use in The Measurement of Road Vehicle Emissions", 2009.

[2] P. Neto, J. N. , Pires, A.P. Moreira, "3-D Position Estimation from Inertial Sensing: Minimizing the Error from the Process of DoubleIntegration of Accelerations", Porto, 2014.

[3] J. Lai, P. Lv, J. Liu, B. Jiang, "Noncommutativity Error Analysis of Strapdown Inertial Navigation System under the Vibration in UAVs.9", 2012.

[4] C. R. Carlson, J.C. Gerdes, J. D. Powell, Nav.51,13-28, 2003.

[5] G. Chugh, D. Bansal, S.Sofat, "Road Condition Detection Using Smartphone Sensors: A Survey.7", Chandigarh, 2014.

[6] S. Stančin, S. Tomažič, "Smartphone MEMS Accelerometer for Cycling-Observations", Ljubljana, 2015

[7] M.E. Diasty, A.E. Rabbany, S. Pagiatakis, "Temperature variation effects on stochastic characteristics for low-cost MEMS-based inertial sensor error.18", 2007.

[8] T. C. Welker, M. Pachter, R. E. Huffman., "Gravity Gradiometer Integrated Inertial Navigation", Zurich, 2013.

[9] J. Mendel, "Fuzzy logic systems for engineering: a tutorial", 1995. 